\title{
Death by negligence
}

\section{John Launer}

My mother died just over 25 years ago, in a hospital bed, from a pulmonary embolus. It was, like most such deaths, entirely unnecessary and preventable. She had a history of deep vein thrombosis (DVT), for which she had previously been admitted to the same hospital. For several days before her death, she had barely left her hospital bed, and had eaten and drunk very little. In spite of all of this, she was not on an intravenous drip, nor wearing anti-embolism stockings. She was also not receiving low molecular weight heparin. On the day of her death, she was complaining of mild diarrhoea, which was almost certainly due to her poor nutritional state. A junior doctor examined her, including a rectal examination, and he almost certainly dislodged a large pelvic thrombus which killed her.

I had qualified as a doctor myself not long previously. Although I believed her care had been negligent, I made no complaint to the hospital. The reasons were complex. These included my own bereaved state, and a wish to avoid an unpleasant and long drawn out fight against a hospital team that showed every sign of being defensive and incapable of admitting fault. Perhaps the most important factor was that I believed that my mother wanted to die. She was not coping well with her widowhood (my father had died the previous year) and she felt overwhelmed by her own infirmities.

\section{INHERITED TENDENCY}

Some years later, I started to suffer from unexplained breathlessness myself and began to have dreams of asphyxiation. I became convinced that I too was suffering from pulmonary emboli. Being a little more senior in the profession by then, I managed to persuade a consultant-in spite of her considerable scepticism-to carry out a perfusion-ventilation scan. This proved my diagnosis correct. I had presumably inherited my mother's thrombophilic tendency. I am now on lifelong warfarin.

Warfarin lowers the risk of recurrent emboli, but of course it does not abolish this. So when I started to wake up breathless again earlier this year, I asked

Correspondence to: Dr John Launer, London Deanery, Stewart House, London WC1B 5DN, UK; jlauner@ londondeanery.ac.uk a GP colleague to arrange for urgent admission, which he immediately did. This time it turned out to be a false alarm, and I probably only had mild bronchospasm. But a day on the acute medical assessment ward-in the hospital where my mother died, as it happenswas educational.

\section{TWO WOMEN}

I was in a four-bedded bay, occupied by two women and one man as well as myself. The other man was being investigated for recent unexplained fits, but he was otherwise alert and ambulant. The two women, however, were obviously unwell. One was a young woman who was flushed and febrile from an acute kidney infection. She was on an intravenous infusion, but when this ran out the bag stayed empty for at least an hour. The nurses, who spent most of the day at their desk, failed to notice until my wife and I pointed it out. We were even more concerned about the other occupant of the bay: an elderly, agitated and dysphasic woman who had had a stroke and could not leave her bed. She was not on a drip and, in the course of the day, she ate and drank virtually nothing. In spite of that, I did not witness any of the nurses trying to help her to do so.

In the afternoon, unable to bear their inaction any more, I went over to her bed and coaxed her to drink half a glass of water. I noted that she too was not wearing anti-embolism stockings. Both she and the young woman with pyelonephritis were almost textbook candidates for getting pulmonary emboli and suffering the same fate as my mother. I cannot be certain whether or not either woman was receiving heparin, but, given the general indifference shown to them, I consider it unlikely.

\section{APPALLING FIGURES}

Writing in Evidence-Based Medicine recently, James Douketis and Nancy Lloyd from Ontario point out that more people die from pulmonary embolism than from breast cancer, AIDS or motor vehicle accidents. ${ }^{1}$ They also cite audits showing that $65-83 \%$ of hospitalised medical patients at risk of DVT do not receive prophylaxis with heparin. Among the reasons they suggest for these appalling figures are that clinicians are slow to change accepted practices, and that they may consider adoption of guidelines as a loss of autonomy. The authors debate various ways of encouraging hospital physicians to put the evidence for embolus prevention into practice, but they also note that interventions aimed at improving clinical guideline adherence confer, on average, only a $10 \%$ improvement. They conclude by proposing that decision makers should challenge physicians to consider prophylaxis for every patient admitted to a medical ward, develop a risk assessment algorithm and standard orders for prophylaxis, and "continue to remind physicians and residents of the need to consider DVT prophylaxis".

I applaud Douketis and Lloyd for drawing everyone's attention-yet again - to the scandalous facts surrounding deaths in hospital from pulmonary emboli, but I question their faith that yet another published list of recommendations in a journal will alter anyone's behaviour one jot. In the light of my mother's death a generation ago, and of my own experience in the last few months, I cannot help asking how much time clinicians should be allowed before they "change accepted practices" or agree to lose their autonomy in the matter of letting people die needlessly. From what I observed on my own hospital ward recently, I would also argue that the decision over whether or not to give heparin is itself only part of the picture. If nursing care on medical wards is globally indifferent or awful, and immobilised patients are starved and dehydrated, the chances of emboli must be greatly multiplied regardless of what appears on the drug chart.

\section{A SIMPLE SUGGESTION}

What then might really make a difference? A colleague of mine has made a simple suggestion. It is litigation. According to him, we should straightforwardly inform people at every opportunity that deaths from pulmonary emboli in hospital, or shortly after discharge, are in almost every case demonstrably related to poor medical and nursing care. We should support families in taking action against hospitals for the loss of their loved ones, and stop covering up the scale of negligence that is taking place, or making it sound as if circumstances are grey when they are really black and white. We should, in other words, provoke an epidemic of legal claims until it brings 
about a decline in the epidemic of iatrogenic deaths from pulmonary emboli.

Should I have sued the hospital when my mother died? In some ways I wish I had. It would have been an ugly and disturbing experience, and it might have done damage to my subsequent career as well. But there is also a chance that it might have led some of the hospital staff to think differently about their duty of care to vulnerable medical patients. It might have helped to save at least some of the pointlessly wasted lives that have been lost in the 25 years since.

Competing interests: None.
Postgrad Med J 2009;85:55-56.

doi:10.1136/pgmj.2008.077966

\section{REFERENCE}

1. Douketis JD, Lloyd NS. Why A-level evidence does not make it to clinicians' A-list: the case of thromboprophylaxis in medical patients. Evid Based Med 2008:13:133-4.

\section{Let us assist you in teaching the next generation}

Figures from all articles on our website can be downloaded as a PowerPoint slide. This feature is ideal for teaching and saves you valuable time. Just click on the image you need and choose the "PowerPoint Slide for Teaching" option. Save the slide to your hard drive and it is ready to go. This innovative function is an important aid to any clinician, and is completely free to subscribers. (Usual copyright conditions apply.) 